\title{
A Note on Writing
}

Before one starts to read this book, I would like to clarify four decisions I made about how to write about policing and violence in South Africa. The first point concerns race. As highlighted by other scholars working on South Africa, race is an inescapable part of South African life, and every ethnographer will have to deal with this issue. Throughout the research process, and particularly during the writing phase, I thought at length about how to approach, define, and discuss issues of race. The diversity of paths taken by other scholars working on and in South Africa did not make this process any easier.

Apartheid legally classified South African society into four racial groups: White/European, Colored, Asian, and African/Native. The term "Black" referred to all "non-Whites." For this book, I employ these same racial categories, because my informants still used them to define themselves and others. However, when I use the term "Black," I am referring to individuals who were previously labeled as "Native" or "African." Another word that I use regularly is "non-White," again because my informants regularly did so. In fact, many informants preferred the label "non-White" to the earlier category of "Black," which encompassed Blacks, Indians, and Coloreds. Like Ashforth (2005), I use capital letters, such as in "White" and "Black," in reference to groups of individuals, particularly as a means of identification. For example, when armed response officers talk of criminals as Blacks, I capitalize the term, because they are making reference to a group of individuals they define according to race. 
When I use these terms as adjectives, such as for "a black armed response officer," I do not capitalize them.

The second point concerns anonymity. Although several informants did not object to their identity being made public, and some even encouraged it, the majority of my interlocutors expressed a desire for anonymity. For the sake of consistency, I have decided to extend anonymity to all parties, including the companies and community organizations that I studied; hence, the use of letters to identify them in Chapters 3 and 6. Furthermore, the industry is highly competitive, and many of those who worked in it, particularly company owners, regularly asked me which company I thought was the "best." I refrained from taking part in this debate, which is another reason for not revealing the names of the companies. Moreover, when discussing particular incidents that occurred during my fieldwork, I refer only to months instead of specific dates. This is intended not only to protect the identities of the armed response officers but also, and in particular, to prevent companies from identifying each other.

However, to be able to follow certain informants throughout this book, I provided particular armed response officers with pseudonyms from a range of names that actually exist to make the names realistic. For example, in Chapter I, I refer to "Bongani;" although this is not the real name of the person being discussed, there is another informant called Bongani. Furthermore, I often use pseudonyms that reflect the racial identity of the informants, such as Sanjeev, a common Indian name that is the pseudonym of one Indian armed response officer. Because I argue that issues of race continue to shape contemporary policing and perceptions of violence, I believe it is important to indicate the racial identities of my informants.

The third point I want to make here is that many of the narratives and quotes in this book have been shortened. However, they have not been altered or corrected in terms of grammar or speech. At a conference, I was once criticized for not removing grammatical errors or swear words, such as "fuck," from my quotes. The person in question argued that my method made my informants look "uneducated" or even "aggressive." Although I understand this point, I do not believe that it is my role to correct or alter the language used by my informants. Rather, I want to give an accurate impression of how they actually speak. I have therefore opted not to remove swear words, slang, or grammatical errors from my quotations. 
The fourth point is a temporal one and concerns the time period in which I conducted the research and that in which this book was written. I conducted my fieldwork between 2007-IO, and when writing my dissertation (that I defended in 20I3), I used data, such as crime statistics, from that time period. In this book, which I completed in early 2015 , the majority of the "numbers" are from the period 20I0-I2, as I believe that it is confusing, and perhaps even unreliable and invalid, to compare data from different time periods. For example, an interview from May 20 IO about one's perceptions of crime should not be supported with, or equated to, a survey conducted in 20I4. This book is therefore about security and violence in Durban, South Africa, from 2007-I 2. However, although certain figures may have changed, the processes and mechanisms that I identify in my book have not. 


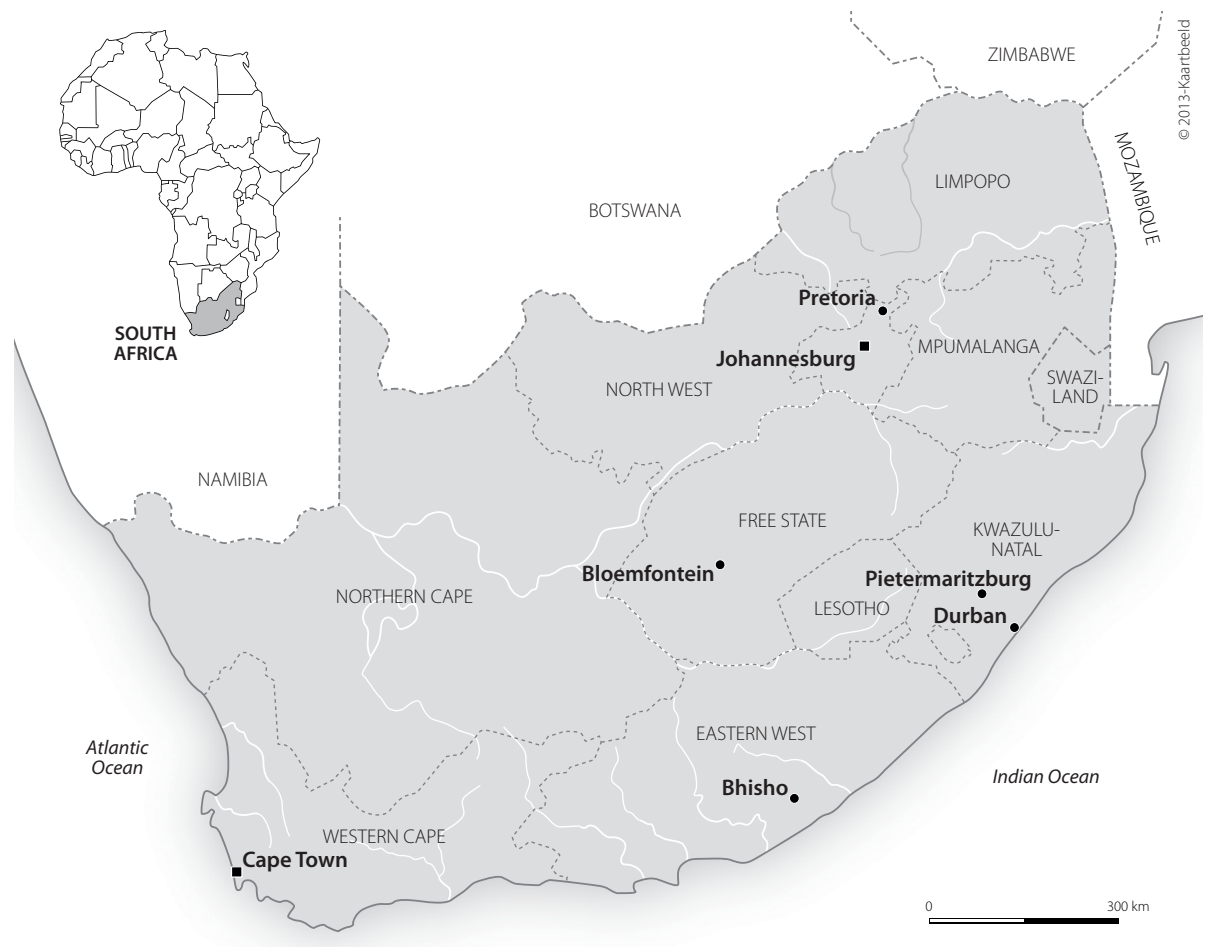

MAP I. South Africa. Copyright 20I3-Kaartbeeld. 


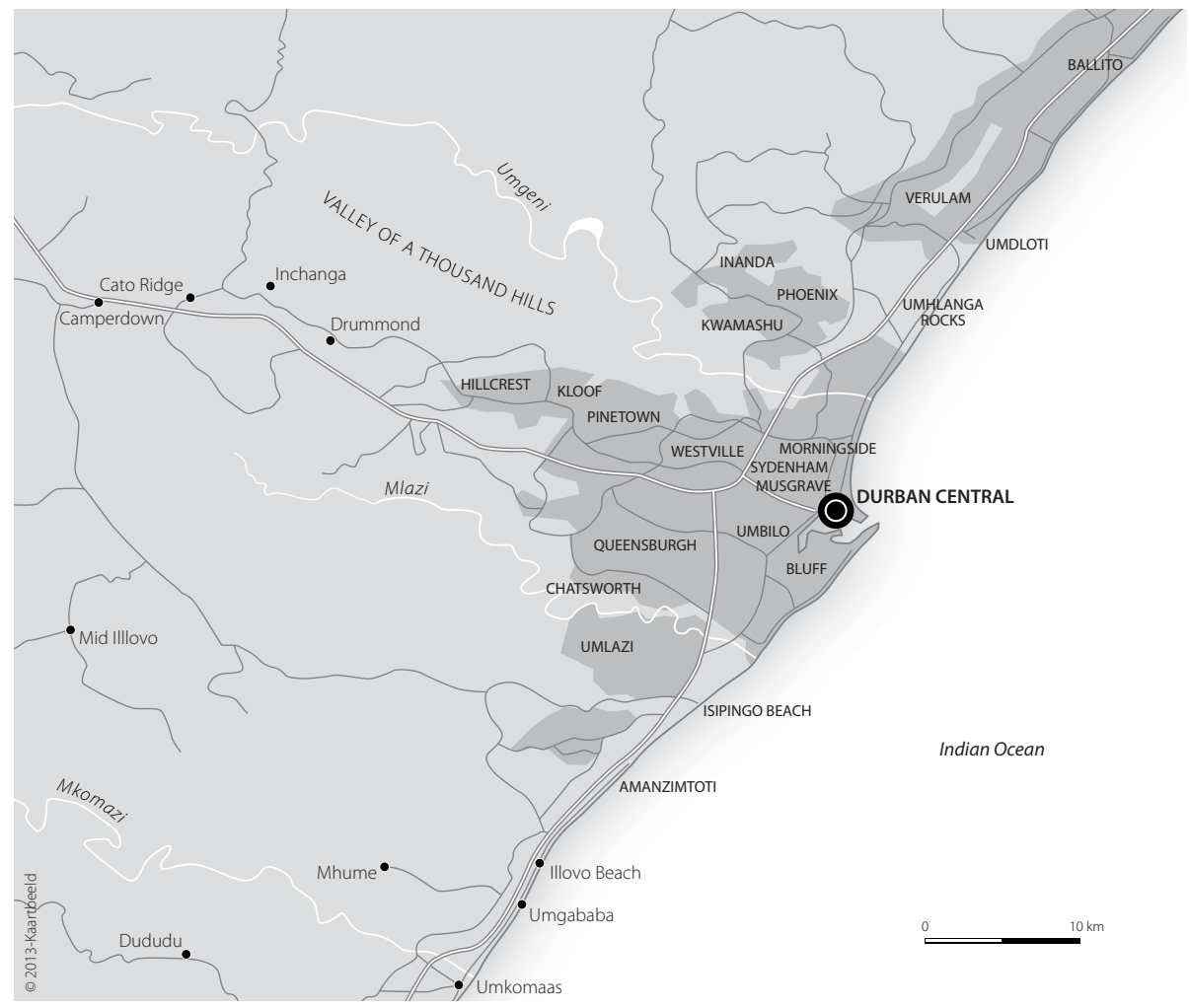

MAP 2. Durban. Copyright 20I3-Kaartbeeld. 
This page intentionally left blank 